\title{
Classification of Family Risk in a Family Health Center
}

\author{
Priscila Tadei Nakata ${ }^{1}$ \\ Lenice Ines Koltermann ${ }^{2}$ \\ Kellyn Rocha de Vargas ${ }^{1}$ \\ Priscilla Wolff Moreira ${ }^{1}$ \\ Êrica Rosalba Mallmann Duarte ${ }^{3}$ \\ Idiane Rosset-Cruz ${ }^{3}$
}

Objective: to identify and classify the degree of family risk in a Family Health Center by means of a multidimensional evaluation instrument. Method: a cross-sectional study, with a quantitative and descriptive design, which evaluated 927 families registered in the center, which covers five micro-areas. The Coelho and Savassi Scale was applied, this consisting of 13 sentinels of evaluation of the social risk, using secondary data available in the File A of the families' medical records, in the last trimester of 2011. The data was analyzed using the SPSS (Statistical Package for the Social Sciences) for Windows software, version 18.0. Results: among the families studied, $68.5 \%$ were classified as not being at risk. It was ascertained that the smallest proportion of at-risk families (8.2\%) was found in micro-area 1, and that micro-area 4 had the highest proportion (55.9\%). The most-prevalent risk situations were poor conditions of basic sanitation, systemic arterial hypertension, diabetes mellitus and drug addiction. Conclusion: this study's results make it possible to create support for the planning of home visits, to implement health surveillance actions, and for health professionals to better understand the vulnerabilities of the families attended.

Descriptors: Social Vulnerability; Family Health; Home Visit.

\footnotetext{
${ }^{1}$ Undergraduate student in Nursing, Escola de Enfermagem, Universidade Federal do Rio Grande do Sul, Porto Alegre, RS, Brazil. 2 MSc, RN, Instituto de Cardiologia do Rio Grande do Sul, Porto Alegre, RS, Brazil.

${ }^{3}$ PhD, Adjunct Professor, Escola de Enfermagem, Universidade Federal do Rio Grande do Sul, Porto Alegre, RS, Brazil.
}

Corresponding Author:

Priscila Tadei Nakata

Universidade Federal do Rio Grande do Sul. Escola de Enfermagem

Rua São Manoel, 963

Bairro: Rio Branco

CEP: 90620-110, Porto Alegre, RS, Brasil

E-mail: priscilanakata@gmail.com 


\section{Introduction}

The Family Health Strategy (FHS) aims to reorganize primary care in Brazil according to the precepts of the Unified Health System (UHS ). It is considered a strategy for the expansion and qualification of this service, as it supports the re-orientation of the work process such that it may have greater potential for deepening its principles and directives and for extending its resolutive power and impact on people and society's health situations, besides providing a cost-effectiveness ratio(1).

The Family Health Centers' (FHC) work process proceeds based on delimitation of the territory in which they act, and surveying and recognition of the allocated area, in which they must carry out actions based on criteria of risks to health, seeking to widen family care practice $^{(2)}$. Health Surveillance is integrated into this work process as an important activity, seeking to identify the health needs of the allocated families ${ }^{(3)}$. For this, it is necessary to investigate the families' structures and functionality, so as to optimize surveillance actions and the resources available, proposing interventions which are commensurate with the needs identified.

A family is considered to be a set of people linked by blood ties and domestic dependence and who are resident in the same house ${ }^{(4)}$, as well as being an indispensable protective unit for its members, as it provides affective, material and educational contributions, necessary for the development and well-being of its components(5).

Therefore, , the assistance to the family as a care unit - proposed by the FHCs, entails the construction of a link between the health professionals and the service users which will allow co-responsibilization for health care $^{(1)}$. For this, the assistance given in this service must not be limited to the direct care to the individual, but must also involve the planning of health actions, taking into consideration that each family has its own way of organizing so as to share care responsibilities(6).

The Home Visit (HV) is one of the FHC's work tools, and allows the service to carry out health promotion activities, activities to prevent harm to health, and health surveillance, in addition to monitoring all the families and individuals under its responsibility, according to the needs defined by the team ${ }^{(2)}$. It is a means of finding out about the population's reality, of establishing links with the service user, and of understanding the dynamics of

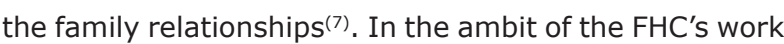
process, it is necessary to establish criteria for planning care, carrying it out, recording data and evaluating the care process.
One of the criteria which has been used for the planning of the HVs and the appropriate allocation of resources is the evaluation of family risk $^{(8-9)}$, through the identification of the risk factors to which the family is exposed. The understanding of each family's life context allows the planning of actions which are specific to each context and which are commensurate with the resources available to each family(7). It was ascertained, however, that there is a shortage of Brazilian studies addressing this issue, to support decision-making in health and to allow intra- and inter-regional comparisons.

Thus, the evaluation of family risk appears as a proposal for differentiating the families belonging to the same area of coverage, so as to identify risk factors which explain the prioritization of attendance. For the present study, risk is related to the identification of the presence of characteristics, whether in the family or in an individual belonging to it, putting it/them at a greater or lesser probability of exposure to factors which are prejudicial to health, and which may come to cause physical, psychological or social harm(9).

In this context, it becomes necessary for the health team to identify the factors which contribute to the situation of family risk. In this way, this study can contribute to the planning of HVs and other surveillance actions, as well as the appropriate allocation of health resources, in a way that prioritizes the most vulnerable families, so as to be fair and provide care in a resolutive way. Therefore, the aim was to identify and classify the degree of family risk in a $\mathrm{FHC}$, as well as the factors which contribute to this, by means of a multidimensional evaluation instrument.

\section{Methods}

This is a cross-sectional study, with a quantitative and descriptive design, undertaken in the Nossa Senhora de Belém FHC in the municipality of Porto Alegre, in the state of Rio Grande do Sul (RS). The center, set up in 2008, covers 3,145 inhabitants, distributed among 929 families. The choice of this locale was owed to the health teams' interest in increasing their knowledge of the families associated to the above-mentioned Health Center, which is a field for placements and undertaking of research projects and extension courses run by the Federal University of Rio Grande's Nursing School (NS/FURG)

The population study was composed of all the families allocated to the above-mentioned center. Two residential homes for the elderly were excluded from 
the study, as, although these were registered in families' medical records, they were characterized differently from the other domiciles. As a result there was a total of 927 families.

For the identification and classification of family risk, the Family Risk Scale was applied(9). This aims to determine the social risk of the families allocated in the FHCs, seeking to reflect the potential for illness of each family nucleus.

The information needed for filling out the abovementioned instrument was collected through consulting the File A from the Primary Care Information System (PCIS)(10), which is used for registering the families in the FHCs. This file, available in the families' medical records, is filled out by the Community Health Workers ( $\mathrm{CHW}$ ), during the first HVs and is updated according to the changes in the family dynamics. No instances of files filled out inadequately were found, and clarifications were sought from the $\mathrm{CHW}$ of the corresponding microarea when necessary.

The Form A covers a series of information which makes it possible to identify the reality in which the families are integrated, this including: identification, demographic and health situation data for all the individuals, separated by age group from 0 to 14 years old and 15 years old and over: date of birth, age, sex, literacy, occupation, illness or condition mentioned, housing situation, and basic sanitation.

The instrument applied is made up of 13 risk sentinels: 11 of individual character, such as people who are bed-ridden, who have a physical disability, a mental disability, or serious malnutrition, these corresponding to three points for each occurrence; drug addiction and unemployment, which correspond to two points for each occurrence; illiteracy, child younger than six months, older adult over 70 years of age, and people with systemic arterial hypertension ( $\mathrm{SAH}$ ) and diabetes mellitus (DM), which correspond to one point for each occurrence on the Scale. The non-individual sentinels are the poor sanitation conditions, which correspond to three points, and the person/room ratio, which scores three points if greater than one, two if equal to one, and zero if less than one. The sum of these items gives a total score, later classified in degrees of risk: a score of 0 to 4 (without risk), a score from 5 to 6 is classified as R1 (low risk), a score of 7 to 8 as R2 (medium risk) and any score over 9 as R3 (maximum risk).

The secondary data was collected in the FHC itself, in the period October - December 2011, by student nurses from the NS/FURG, through consultation of the PCIS File A of the families attended in the abovementioned health service.

The data was tabulated in the Excel program and transported to the SPSS program for Windows, version 18.0, for the undertaking of statistical analysis. The value of $p<0.05$ was considered statistically significant.

The research project was approved by the Research Ethics Committee of the Porto Alegre (RS) Municipal Health Department under Decision n. 001.036704.11.3.

\section{Results}

Of the 927 families evaluated, it was observed that the majority 635 (68.5\%) did not present risk situations. However, it stands out that a significant number of families (292-31.5\%) presented some type of risk. Table 1 shows the differences between the mean and the Standard Deviation (SD) of the risk score according to each Micro-Area (MA) evaluated.

Table 1 - Distribution of Means and Standard Deviation (SD) of the risk scores according to the micro-areas of the FHC evaluated in Nossa Senhora de Belém, Porto Alegre, RS, Brazil, 2011

\begin{tabular}{lcccc}
\hline \multirow{2}{*}{$\begin{array}{c}\text { Micro-areas } \\
\text { (MA) }\end{array}$} & \multicolumn{2}{c}{ Total of families } & $\begin{array}{c}\text { Mean of Risk } \\
\text { Scores }( \pm \text { SD) }\end{array}$ & $\mathbf{p}^{*}$ \\
\cline { 2 - 4 } & $\mathbf{N}$ & $\%$ & $1.55 \pm 1.81$ & $<0.001$ \\
\hline MA 1 & 220 & 23.7 & $3.02 \pm 292$ & \\
MA 2 & 178 & 19.2 & $2.84 \pm 2.68$ & \\
MA 3 & 172 & 18.5 & $5.17 \pm 2.29$ & \\
MA 4 & 229 & 24.7 & $3.96 \pm 2.51$ & \\
MA 5 & 128 & 13.8 & $3.3 \pm 2.75$ & \\
Total & 927 & 100 & &
\end{tabular}

*ANOVA test

In relation to the proportion of families at risk, according to the data in Table 2, it was observed that in relation to the families with some degree of risk, the majority 175 (59.9\%) presented lower risk, it being the case that the highest score found for the maximum risk was 15 points on the Scale. It stands out that MA4 presented a higher proportion of families classified as Risk 3, that is, at higher risk, different from MA1 which presented only one family classified with this degree of risk.

The variables which most contribute to the families' situation of risk, according to the data presented in Table 3 , were the poor sanitation conditions in $41 \%$ of these families, followed by systemic arterial hypertension (SAH) (31.4\%) and drug addiction (18.2\%).

It was also observed that the micro-area with the highest proportion of families at risk was that which 
presented the highest number of families with conditions of poor sanitation, drug addiction, unemployment and presence of SAH and DM.

In relation to the presence of risk sentinels in the families evaluated, those referent to children younger than six months, older adults aged over 70, and SAH were the most frequent in the families categorized as not being at risk. In relation to those classified with some degree of risk, what stood out was the poor conditions of sanitation, drug addiction, $\mathrm{SAH}$, and the person/room ratio greater than 1 .

Table 2 - Classification of families according to the family risk, by MA, in the FHC in Nossa Senhora de Belém, Porto Alegre, RS, Brazil, 2011

\begin{tabular}{|c|c|c|c|c|c|c|c|}
\hline \multirow{2}{*}{$\begin{array}{l}\text { Micro-areas } \\
\text { (MA) }\end{array}$} & \multicolumn{2}{|c|}{ Families not at risk } & \multicolumn{3}{|c|}{ Families at risk } & \multicolumn{2}{|c|}{ Total of families at risk } \\
\hline & $\mathbf{N}$ & $\%$ & Risk 1 & Risk 2 & Risk 3 & $\mathbf{N}$ & $\%$ \\
\hline MA 1 & 202 & 91.8 & 12 & 5 & 1 & 18 & 8.2 \\
\hline MA 2 & 130 & 73 & 25 & 13 & 10 & 48 & 27 \\
\hline MA 3 & 129 & 75 & 27 & 11 & 5 & 43 & 25 \\
\hline MA 4 & 101 & 44.1 & 71 & 39 & 18 & 128 & 55.9 \\
\hline MA 5 & 73 & 57 & 40 & 10 & 5 & 55 & 43 \\
\hline Total & 635 & 68.5 & 175 & 78 & 39 & 292 & 31.5 \\
\hline
\end{tabular}

Table 3 - Distribution of the risk sentinels present in families attended in the FHS center in Nossa Senhora de Belém, Porto Alegre, RS, Brazil, 2011

\begin{tabular}{|c|c|c|c|c|c|}
\hline \multirow{2}{*}{ Sentinels } & \multirow{2}{*}{ Not at risk } & \multirow{2}{*}{ At risk } & \multicolumn{2}{|c|}{ Total } & \multirow{2}{*}{$\mathbf{p}^{*}$} \\
\hline & & & $\mathbf{N}$ & $\%$ & \\
\hline Bed-ridden & 1 & 10 & 11 & 1.2 & $<0.001$ \\
\hline Physically disabled & 6 & 16 & 22 & 2.4 & $<0.001$ \\
\hline Mentally disabled & 5 & 22 & 27 & 2.9 & $<0.001$ \\
\hline Poor sanitation conditions & 155 & 225 & 380 & 41 & $<0.001$ \\
\hline Malnutrition & - & 3 & 3 & 0.3 & 0.011 \\
\hline Drug addiction & 34 & 135 & 169 & 18.2 & $<0.001$ \\
\hline Unemployment & 6 & 52 & 58 & 6.2 & $<0.001$ \\
\hline Illiteracy & 10 & 29 & 39 & 4.2 & $<0.001$ \\
\hline Child below six months & 11 & 7 & 18 & 1.9 & 0.49 \\
\hline Older adult over 70 years old & 48 & 42 & 90 & 9.7 & 0.001 \\
\hline Systemic Arterial Hypertension (SAH) & 175 & 116 & 291 & 31.4 & $<0.001$ \\
\hline Diabetes mellitus (DM) & 35 & 58 & 93 & 10.1 & $<0.001$ \\
\hline Person/room ratio $^{\dagger}$ & 108 & 139 & 247 & 14.8 & $<0.001$ \\
\hline
\end{tabular}

*Chi-squared test

tFor this sentinel, families were considered which scored the values (2) or (3)

It was observed that the means of family risk were significantly higher in families with the presence of any of the sentinels, when compared to those with the respective sentinels absent (Table 4 ). The highest variation in means occurred between families presenting individuals with malnutrition and unemployment, when compared to the means of risk of those with these sentinels absent. (Table 4).

Table 4 - Distribution of mean of family risk according to the presence or absence of the sentinels in the families evaluated. Porto Alegre, RS, Brazil, 2011

\begin{tabular}{lcc}
\hline \multicolumn{1}{c}{ Sentinels } & Present (mean \pm SD) & Absent (mean \pm SD) \\
\hline Bed-ridden & $6.55( \pm 1.75)$ & $3.26( \pm 2.74)$ \\
Physically disabled & $6.95( \pm 3.44)$ & $3.21( \pm 2.68)$ \\
Mentally disabled & $7.15( \pm 3.25)$ & $3.18( \pm 2.66)$ \\
Poor sanitation conditions & $5.31( \pm 2.37)$ & $1.90( \pm 2.05)$
\end{tabular}


Table 4 - (continuation)

\begin{tabular}{lccc}
\hline \multicolumn{1}{c}{ Sentinels } & Present $($ mean \pm SD) & Absent $($ mean \pm SD) & $\mathbf{p}^{*}$ \\
\hline Malnutrition & $11.0(.61)$ & $3.27( \pm 2.72)$ & $<0.001$ \\
Drug addiction & $6.25( \pm 2.65)$ & $2.64( \pm 2.31)$ & $<0.001$ \\
Unemployment & $7.57( \pm 3.12)$ & $3.01( \pm 2.48)$ & $<0.001$ \\
Illiteracy & $6.41( \pm 3.27)$ & $3.16( \pm 2.65)$ & $<0.001$ \\
Child younger than six months & $5.0( \pm 2.61)$ & $3.27( \pm 2.75)$ & $<0.001$ \\
Older adult over 70 years old & $4.36( \pm 2.44)$ & $3.19( \pm 2.76)$ & $<0.001$ \\
Systemic Arterial Hypertension & $4.09( \pm 2.71)$ & $2.94( \pm 2.70)$ & $<0.001$ \\
Diabetes mellitus & $5.18( \pm 2.71)$ & $3.09( \pm 2.68)$ & $<0.001$ \\
Person/room ratio & $5.15( \pm 2.76)$ & $2.63( \pm 2.43)$ & $<0.001$ \\
\hline
\end{tabular}

* Student T test

tFor the presence of this sentinel, families were considered which scored the values (2) or (3).

\section{Discussion}

Comparative analysis was difficult because there are few studies in the literature addressing family risk. It is also considered that although the areas covered by the FHC correspond to those which are more vulnerable, there are important inter- and intra-regional geographical and socio-economic differences, which may possibly interact with a community's health conditions.

The differences found in the present study between the mean family risk scores between the micro-areas indicate that although these families belong to the same FHC coverage area, there are important divergences regarding the social aspects which may influence the individuals' state of health. Social inequality impacts quality of life and, as a result, the health of the families and the individuals, as health is related to suitable living conditions and to fair social and economic policies ${ }^{(11)}$. Hence, these results can contribute as much to the planning of HVs and other health surveillance actions as to the appropriate allocation of resources, among the health care directed at these families in the $\mathrm{FHS}^{(12)}$.

The differences found in the present study indicated micro-area 4 as having the highest mean risk score, this standing out from the others. This suggests the importance of there being local planning which is differentiated, taking into account an area's specific characteristics. The characteristics of a specified community correspond to a diversity and complexity of factors which influence the local health and how these variables relate to each other(12).

In this research, the largest proportion of the families evaluated is classified as not at risk (68.5\%). One study ${ }^{(9)}$ undertaken in a FHC in the municipality of Contagem in the Brazilian state of Minas Gerais also found a higher proportion of families not at risk, albeit at a significantly higher percentage than in the present study (96\%). In contrast, another investigation(8) carried out in Espírito Santo State showed that $55.4 \%$ of the families evaluated presented some type of risk. These results show that although the FHC have more vulnerable areas as their principal fields of action, there are nevertheless important local differences which must be taken into account in the planning of the health actions performed by these teams. The fact that MA1 presented a significantly lower proportion of at-risk families and that MA4 presented a higher proportion, in comparison with the others, may, among other aspects, be reflecting important socioeconomic and health differences within the same area of FHC coverage. MA1 is more urbanized and has better conditions of paving, housing and basic sanitation when compared to the others, which may have contributed - at least partially - to these local differences.

The Ministry of Health proposes that FHS actions - such as HVs, health surveillance actions, and the allocation of primary care resources - should be planned based on risk criteria, that is, prioritizing individuals and families in situations of greater need and vulnerability ${ }^{(13)}$. The assessment of family risk based on a scale with domains corresponding to the various areas of health makes it possible to analyse the situation of each item in an inter- and multi-disciplinary way. In addition to this, it encompasses characteristics of the environment in which the family is located, which backs up another study ${ }^{(8)}$, which proposes that the condition of family risk is also related to social factors.

Poor sanitation conditions - the most prevalent sentinel among the total of families as well as among those at risk - is of extreme importance, as inadequate sanitation infrastructure is related to situations of greater risk or social vulnerability, and greater morbidity and mortality ${ }^{(14)}$.

The SAH, on the other hand, the second most prevalent sentinel in the total of the families, was more 
prevalent in the not-at-risk families than in those at risk. This situation shows that some non-communicable diseases (NCD), although constituting a health problem of great magnitude in Brazil, may not influence an increase in families' risk or vulnerability if appropriately managed. They strongly affect poor segments of the population and vulnerable groups, corresponding to $72 \%$ of the causes of death and $75 \%$ of the healthcare costs in the SUS. This fact shows further the importance of the attention to the treatment of these diseases in primary care, as to be controlled appropriately, these require a combination of medications and non-medication-based measures, entailing comprehensive and continuous care on the part of the health professionals ${ }^{(15)}$.

Estimates show prevalences of $5.2 \%$ of diabetes and $21.4 \%$ of $\mathrm{SAH}$ in the city of Porto Alegre ${ }^{(16)}$. The fact that 174 (59.6\%) of the at-risk families have one or more family member with SAH and/or DM requires greater attention in the carrying-out of health actions directed at not only the treatment but also at the prevention of further cases.

Drug addiction, the third most prevalent sentinel among all the families evaluated, was substantially more present in the at-risk families. It is emphasized that the use of drugs may be related to other social factors, such as unemployment(17), which is also a fairly prevalent sentinel in the at-risk families in the present investigation. Unemployment, identified in $52(17.8 \%)$ of the $292(100 \%)$ at-risk families, is an important factor for vulnerability, as the health of an individual is related to the social determinants of health ${ }^{(3,18)}$. Furthermore, unemployment can cause insecurity, stress and a greater tendency to alcoholism and other drugs, which can in their turn trigger other health problems.

The number of at-risk families with a family member with a mental illness is another factor which must be taken into account in the planning of the FHC's health actions for the community, as often the area in which associated communities are found lacks spaces with support networks which help in the assistance of these people. The social support networks can represent an optimizing element for the reduction of other healthrelated problems, as they promote greater social participation and community inter-relations, producing self-confidence and the power to cope with adversities in the individuals' daily lives ${ }^{(19)}$.

The high mean on the risk scale of families with individuals with malnutrition, followed by those with unemployment, shows the inter-relation between social factors and health factors ${ }^{(20)}$, emphasizing the importance of a joint approach in the continuous and comprehensive care given by primary care professionals. The SAH and DM sentinels, on the other hand, presented both among the lowest means on the scale - considering the families in which these are found - and the lowest variability among families in which they are found and in which they are not. It is possible that individuals with appropriately controlled NCD may not necessarily present other social or health problems.

It is important, however, to take into account that the fact of the scale being composed of various self-reported events implies possible divergence between the information collected and the population's real situation.

The union of various risk factors in one family makes it more vulnerable and with more problems, especially in the care which must be given to the children and that required by the older adults. These population groups in general are more dependent on care, which in most cases is provided by a family member. The family is, often, the ill individuals' first source of care, such that most of the symptoms are treated without coming to the attention of the health services network ${ }^{(21)}$. It is in the family that the health care - which can contribute to compliance with treatment, and make the patient's inclusion in their care possible - is produced(22-23). For this, affective, responsible interactions are necessary between their members, which must be stimulated by the FHC professionals, considering the link which these maintain with the community. Also important are improvements in the families' living conditions, through social policies which transcend the sectorial approach and identify with the family as a cohesive and pro-active unit in the resolution of its problems ${ }^{(23)}$.

\section{Conclusions}

The present study's results show that a significant proportion $(31.5 \%)$ of the families registered in a $\mathrm{FHC}$ was classified as having some degree of risk, indicating a condition of social and health vulnerability of them. The identification and classification of the degree of family risk, as well as the factors which contribute to this, through a multidimensional assessment instrument, was shown to be a useful tool for the appropriate planning and directing of public health policies.

It may also be observed that the area covered by the FHC studied is composed of micro-areas with different levels of family risk, reflecting the need to 
establish strategies to prioritize actions for those with the greatest need. This study's results make it possible for health professionals to understand better the vulnerabilities of the families attended, seeking to contribute to the redirecting of the health care. It is also understood that these findings must be discussed with the center's team and with the families in the territory, through the local health council, as well as with the municipal bodies responsible for improvements in the local sanitary conditions.

\section{References}

1. Ministério da Saúde (BR). PNAB Política Nacional de Atenção Básica. Brasília (DF): Ministério da Saúde; 2012.

2. Ministério da Saúde (BR). Portaria n648/GM de 28 de março de 2006. Aprova a Política Nacional de Atenção Básica, estabelecendo a revisão de diretrizes e normas para a organização da Atenção básica para o Programa de Saúde da família e o programa de Agentes Comunitários de Saúde. Brasília; 2007.

3. Silva TMR, Alvarenga MRM, Oliveira MAC. Evaluation of the vulnerability of families assisted in Primary Care in Brazil. Rev. Latino-Am. Enfermagem. 2012; 20(5):935-43.

4. Instituto Brasileiro de Geografia e Estatística [Internet]. Rio de Janeiro: IBGE; 2012 [acesso em: 12 mar 2012]. Disponível em: http://www.ibge.gov.br/ ibgeteen/pesquisas/família.html

5. Gomes MA, Pereira MLD. Família em situação de vulnerabilidade social: uma questão de políticas públicas. Cien Saude Colet. 2005;10(2):113-28.

6. Ortiz MC, Río CJ, Rodríguez MDCP, Blanco MLH, Robaina NF. Mudanças no contexto do cuidado: desafios para a enfermagem. Rev. Latino-Am. Enfermagem. 2011;19(4):1039-46.

7. Sakata KN, Almeida MCP, Alvarenga AM, Craco PF, Pereira MJB. Concepções da equipe de saúde da família sobre as visitas domiciliares. Rev Bras Enferm. 2007;60(6):659-64.

8. Nascimento FG, Prado TN, Galavote HS, Maciel PA,Lima RCD, Maciel ELN. Aplicabilidade de uma escala de risco para organização do processo de trabalho com famílias atendidas na Unidade Saúde da Família em Vitória (ES). Cien Saude Colet. 2010;15(5):2465-72.

9. Coelho FLG, Savassi LCM. Aplicação de Escala de Risco Familiar como instrumento de priorização das Visitas Domiciliares. Rev Bras Med Fam Comunidade. 2004;1(2):19-26.
10. Ministério da Saúde (BR). Secretaria de Políticas

de Saúde, Secretaria de Assistência à Saúde, Coordenação de Saúde da Comunidade, Departamento de Atenção Básica. SIAB: manual do sistema de Informação de Atenção Básica. Brasília (DF): Ministério da Saúde; 1998.

11. Ministério da Saúde (BR). Projeto Promoção de Saúde: Declaração de Alma-Ata, Carta de Ottawa, Declaração de Adelaide, Declaração de Sundsval, Declaração de Santa Fé de Bogotá, Declaração de Jacarta, Rede dos Mega Países, Declaração do México. Brasília (DF): Ministério da Saúde; 2001. 61 p.

12. Cezar-Vaz MR, Soares MCF, Martins SR, Sena J, Santos LR, Rubira LT, et al. Saber ambiental: instrumento interdisciplinar para a produção de saúde. Texto Contexto Enferm. 2005;14(3):391-7.

13. Ministério da Saúde (BR). Secretaria de Atenção a Saúde. Departamento de Atenção básica. Guia Prático do Agente Comunitário de Saúde. Brasília (DF): Ministério da Saúde; 2009. 260 p.

14. Ventura RN, Oliveira EM, Silva EMK, Silva NN, Puccini RF. Condições de vida e mortalidade infantil no município do Embu. Rev Paul Pediatr. 2008;26(3):251-7.

15. Ministério da Saúde (BR). A vigilância, o controle e a prevenção das doenças crônicas não transmissíveis. [Internet]. 2005. [acesso 2 ago 2012]. Disponível em http://portal.saude.gov.br/portal/arquivos/pdf/doencas_ cronicas.pdf

16. Schmidt MI, Duncan BB, Hoffmann JF, Moura L,Malta DC,Carvalho RMSV. Prevalência de diabetes e hipertensão no Brasil baseada em inquérito de morbidade auto-referida, Brasil, 2006. Rev Saude Pública. 2009; 43(supl 2):74-82.

17. Guimarães JMX, Vasconcelos EE, Cunha RS, Melo RD, Pinho LF. Estudo Epidemiológico da violência por arma branca no município de Porto Grande, Amapá. Cienc Saude Coletiva. 2005;10(2):441-51.

18. Buss $P$, Pelegrini FA. A saúde e seus determinantes sociais. Rev Saúde Coletiva. 2007;17(1):77-93.

19. Comissão Nacional sobre Determinantes Sociais da Saúde. Relatório final da Comissão Nacional sobre Determinantes Sociais da Saúde. CNDSS [Internet]. Rio de Janeiro; 2008 [acesso 6 dez 2008]. Disponível em: http://www.cndss. fiocruz.br/pdf/home/relatorio.pdf. 20. World Health Organization (WHO). 2007 [acesso 8 ago 2012]. Disponível em: http://www.who.int/social_ determinants/resources/gkn_hawkes.pdf

21. Leite SN, Vasconcelos MPC. Negociando fronteiras entre culturas, doenças e tratamentos no cotidiano familiar. História Ciênc Saúde. 2006;13(1):113-28. 
22. Gutierrez DMD, Minayo MCS. Produção de conhecimento sobre cuidados da saúde no âmbito da família. Cien Saude Colet [serial on the Internet]. [acesso 14 mai 2012]. Disponível em: http://www.scielo.br/ scielo.php?script=sci_arttext\&pid=S1413

23. Zabala Arguelles MC. Poverty and Vulnerability in Cuba today. Soc Democracy. 2010;24(Spec Number 1: Cuban Perspectives Cuban Socialism):109-26. 